Philosophie ANTIQUE

\section{Philosophie antique}

Problèmes, Renaissances, Usages

15 | 2015

Questions sur le scepticisme pyrrhonien

\title{
Scepticism, number and appearances
}

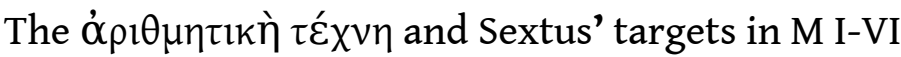

\section{Lorenzo Corti}

\section{(2) OpenEdition \\ Journals}

Electronic version

URL: https://journals.openedition.org/philosant/376

DOI: 10.4000/philosant.376

ISSN: 2648-2789

\section{Publisher}

Éditions Vrin

\section{Printed version}

Date of publication: 24 November 2015

Number of pages: $121-145$

ISBN: 978-2-7574-1141-4

ISSN: 1634-4561

\section{Electronic reference}

Lorenzo Corti, "Scepticism, number and appearances", Philosophie antique [Online], 15 | 2015, Online since 01 November 2018, connection on 03 December 2022. URL: http://journals.openedition.org/ philosant/376 ; DOI: https://doi.org/10.4000/philosant.376

\section{(c) (i) (9)}

Creative Commons - Attribution-NonCommercial-NoDerivatives 4.0 International - CC BY-NC-ND 4.0 https://creativecommons.org/licenses/by-nc-nd/4.0/ 
SCEPTICISM, NUMBER AND APPEARANCES : The dैpı $\theta \mu \eta \tau \iota k \dot{~} \tau \dot{\varepsilon} \chi \nu \eta$ and Sextus' targets in $M$ I-VI Lorenzo CORTI

Archives Henri Poincaré (Nancy)

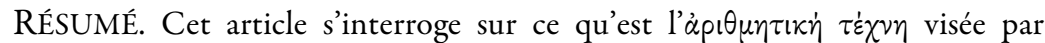
Sextus dans le Contre les arithméticiens. Après avoir rappelé brièvement le contenu de $M \mathrm{IV}$, on examine la nature de cette discipline. Une fois clarifiée la question de savoir en quoi consistait l'ápı $\theta \mu \eta \tau \iota \kappa \eta \dot{~} \tau \dot{\varepsilon} \chi \nu \eta$ dans l'Antiquité - et donc ce que visait Sextus dans $M$ IV -, on examine son rapport avec les autres disciplines critiquées par Sextus dans le Contre les Professeurs. Cette enquête mène à mettre en lumière une importante présupposition implicite dans l'attitude de Sextus à l'égard des sciences.

Summary. This paper is devoted to Sextus' target in Against the Arithme-

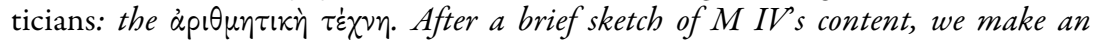
inquiry on the nature of such a discipline. Firstly we tackle the general question of

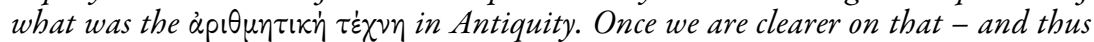
on Sextus' target in MIV, we explore its relationship to the other disciplines attacked by Sextus in his Against the Professors. This ultimately leads us to shed light on an important implicit assumption of Sextu' attitude towards the sciences. 



\section{Exordium: $M \mathrm{IV}$ in the context of $M \mathrm{I}-\mathrm{VI}$}

The subject of this presentation will be Sextus Empiricus' treatise Against the Arithmeticians. This treatise belongs to one of the three surviving works of Sextus, i.e. M I-VI, often called Against the Professors. M IVI is usually characterized as Sextus' most mature work. In $P H$ and in $M$ VII-XI, Sextus provides a sceptical attack on the three constituent parts of philosophy - logic, physics and ethics, and recommends suspension of judgement over every object of inquiry. In $M$ I-VI, by contrast, the targets are more specific: Sextus trains his fire on alleged sciences or branches of putative knowledge ( $\mu \alpha \theta \dot{\eta} \mu \alpha \tau \alpha)$, and the scepticism he encourages often seems to be moderate - or rational - in its scope and nature.

$M \mathrm{I}-\mathrm{VI}$ is structured in three main parts. After a proem (I 1-8) the work divides into two parts: first, a brief general discussion (M I 9-40) and then a particular treatment of individual sciences. In the particular treatment Sextus deals with six $\mu \alpha \theta \dot{\eta} \mu \alpha \tau \alpha$ : with grammar in $M$ I, with rhetoric in $M$ II, with geometry in $M$ III, with arithmetic in $M$ IV, with astronomy in $M \mathrm{~V}$ and with music in $M$ VI. The topics discussed by Sextus in $M$ I-VI constituted a set of liberal arts or $\tau \dot{\varepsilon} \chi v \alpha \iota$ which later formed the trivium and the quadrivium. This set included also logic or dialectic, which Sextus does not discuss in Against the Professors because - it has been argued - he has already dealt with it as one of the three parts of philosophy. ${ }^{1}$

Against the Arithmeticians is articulated in three parts. In the first one (IV 1) Sextus distinguishes two kinds of quantity, namely magnitude and number, which are the subject respectively of geometry and arithmetic, and he announces his aim: to destroy number and to show that the art which is constructed to handle it does not exist. In the second part (IV 2-10) Sextus sketches the 'Pythagorean' philosophy of number, which is a system based on two principles: the One and the Dyad. In the third part (IV 10-34)

1. See Barnes 1988, 56-57; on the relationship between the set of disciplines attacked by Sextus and those forming the trivium and the quadrivium see Spinelli 2010, 249-252, with references. 
Sextus objects in various ways to the principles of this system, i.e. to the Platonic notions of the One (11-20) and of the Dyad (21-2); and finally he puts forward arguments of an entirely abstract nature against the intelligibility of subtraction and addition (23-34).

Sextus's objection against the notion of the One is constituted by two parts. First of all Sextus presents two characterizations of the One which he ascribes to Plato:

- 'One is that without which nothing is called one';

- 'One is that by participation in which each thing is called both one and many'.

The two characterizations are followed by an argument in their support, which aims to show that the One cannot be one of the things which are called one, but must be something different from them, in which they participate. Sextus, then, puts forward two objections against this conception. The first can be sketched as follows: either the idea of One is different from the particular numerables, or it is conceived along with those things which participate in it; but both possibilities lead to difficulties. The second objection argues that, given the idea of the One, by participation in which a thing is called one, either there is one such idea, or there are many ideas of the One. But both possibilities lead to difficulties. As far as the Platonic notion of the Dyad is concerned, Sextus, after having stressed that this concept is subject to an aporia which Plato himself recognized (Phaedo, 96e-97a) concludes that the Dyad is nothing; and therefore number is nothing. ${ }^{3}$ I will not give the details of Sextus' two arguments against the intelligibility of subtraction and addition. ${ }^{4}$ It is worth observing, though, that those arguments have the aim of showing that the dogmatic conception of number is incoherent:

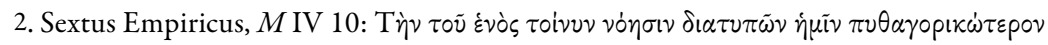

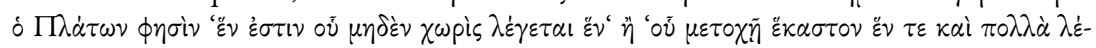
$\gamma \varepsilon \tau \alpha l^{\prime}$. For the passages from $M$ I-VI I use the translation by Bury, sometimes slightly modified.

3. For an analysis of Sextus' attack on the Dyad and its Platonic background see Corti forthcoming.

4. An analysis of these arguments (and of the whole $M$ IV) will be provided in Sextus Empiricus. Against the Arithmeticians, introduction, translation and commentary by Corti forthcoming. 
If number is conceived as subsisting through addition, as I said, and subtraction, and we have shown that neither of these exist, one must declare that number is nothing. ${ }^{5}$

A couple of points are worth emphasising. Sextus' criticism is not addressed against the ordinary arithmetic, the fact of counting or calculating. Indeed, in a parallel passage Sextus seems to accept such activities:

So far as ordinary custom goes, we speak, without holding opinions, of numbering things and we accept that there are such things as numbers. But the superfluities of the Dogmatists have provoked an argument against number too. ${ }^{6}$

Sextus' criticism is rather addressed to the use of arithmetic made by a specific philosophical school. Despite the fact that he calls his adversaries 'Pythagoreans', Sextus' target does not seem to be Pythagoras, but rather philosophers who, using some texts by Plato and his immediate successors in the Old Academy, have developed a doctrine of the incorporeal - and of number in particular. ${ }^{7}$ It should be stressed that Sextus, in the parallel passage $P H$ III 156, ascribes to the Pythagoreans the same argument which he ascribes to Plato in $M$ IV 11-13 - an argument which aims to show that number is something different (has an independent existence) from the numerables.

In order to get clearer on Sextus' target let us go back to the beginning of Against the Arithmeticians:

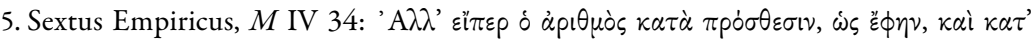

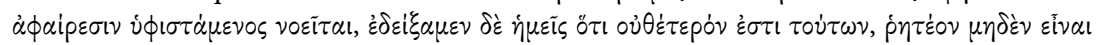
àpituóv.

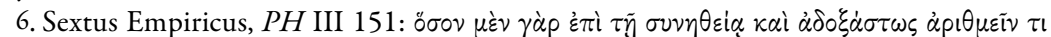

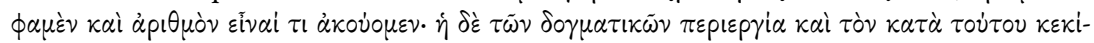

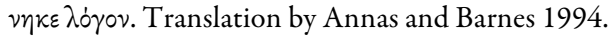

7. The point was made by Burkert 1972, 53-83. In addition to $M$ IV 2-10, Sextus provides what he presents as a Pythagorean doctrine devoted to numbers in three other loci: $P H$ III 151-6 and $M \mathrm{X}$ 248-84, which are subsequently attacked (in $P H$ III 156-67 and $M \mathrm{X}$ 284-309 respectively), and $M$ VII 92-109. Sextus' four accounts were considered among the most important later sources for Pythagoreanism, along with the Pythagorean Commentaries excerpted by Alexander Polyhistor (contained in DL VIII), the Life of Pythagoras excerpted by Photius and the reports of the doxographer Aëtius. All these sources ascribe to the Pythagoreans a doctrine characterised by two principles, the One and the Dyad, and a system in which the geometrical items (the point, the line, the surface and the solid) are somehow derived from the first four numbers. Burkert persuasively argued that the doctrine of the Two Principles and of the Derivation System is not a Pythagorean doctrine, held by Pythagoras or one of his followers, but an achievement of Plato and the Academy, which had its origin in Plato's Timaeus and unwritten doctrines, and the works of his pupils Speusippus and Xenocrates. Cf. infra, n. 23 p. 134. 
Since one kind of quantity, which is called 'magnitude', and which is the chief concern of geometry, belongs to continuous bodies, and another kind, which is number, the subject of the arithmetical [art], belongs to discontinuous things, let us pass on from the principles and theorems of geometry and examine also those which deal with number; for if this is destroyed, the art which is constructed to handle it will not exist. ${ }^{8}$

The scenario is the following. There are two kinds of items: the continuous ( $\sigma \nu \vee \chi \tilde{\eta})$ - the bodies; and the discontinuous $(\delta เ \varepsilon \sigma \tau \tilde{\omega} \tau \alpha)$. And there are two kinds of quantity ( $\pi \circ \sigma \circ \nu)$ : the first is called 'magnitude' ( $\mu$ ' $\gamma \varepsilon \theta \circ$ ) ), and it belongs to continuous items. And the second is called 'number' (aptQuós), and it belongs to discontinuous items. The first kind of quantity, magnitude, is the subject of geometry. The second kind of quantity, number, is the subject of the arithmetical art.

Now Sextus, in $M$ IV, wants to destroy number, and show that the arithmetical art ( $\dot{\alpha} \rho \theta \mu \eta \tau \iota k \dot{\eta} \tau \dot{\varepsilon} \chi \nu \eta)$ does not exist. But what is the discipline which Sextus attacks? The question needs to be answered: surely what he is attacking in IV 2-34 must be the thing he describes in IV 1. And that's what he calls ápı $\theta \eta \eta \tau \iota \dot{\eta}$ or 'arithmetic', as the scholars usually translate;' but of course, this is not the sort of thing we learn in primary schools, which ' $4 \times 7=28$ ' is a theorem of.

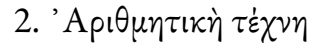

If we want to grasp what is the discipline attacked by Sextus in $M$ IV we have first of all to get clearer on what was the $\alpha p i \theta \eta \eta \tau i k \dot{\eta} \tau \dot{\varepsilon} \chi \nu \eta$ in Antiquity. We may distinguish several approaches to arithmetic in ancient times. The first is represented by books VII, VIII and IX of Euclid's Elements, the so called 'arithmetical books', which constitute the only Greek document preserved devoted to the theory of numbers and proceeding in a demonstrative way. A second approach is constituted by the metaphysical and mathematical account of numbers contained in texts by neo-Pythagorean or Platonist authors. We may mention here Nichomachus of Gerasa $\left(1^{\text {st }}-2^{\text {nd }}\right.$ century $\left.\mathrm{AD}\right)$ and his Introduction to Arithmetic; the commentaries on Nicomachus' Introduction to Arithmetic - in particular, that by Iamblichus of Chalcis $\left(3^{\text {rd }}-4^{\text {th }}\right.$ century AD) which, despite its traditional title, is rather a treatise on numbers based on the Introduction than a com-

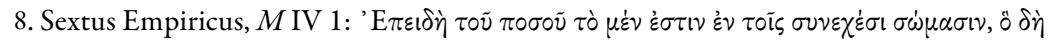

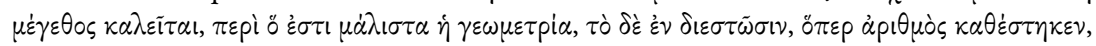

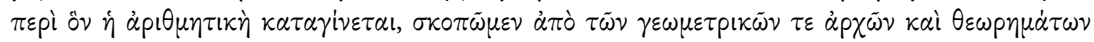

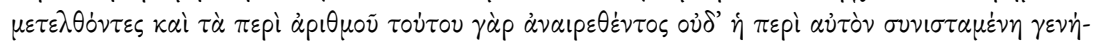
$\sigma \varepsilon \tau \alpha \iota \tau \dot{\varepsilon} \chi \nu \eta$.

9. Cf. Bury 1933: 'arithmetic'; Delattre (in Pellegrin 2002): 'arithmétique'. 
mentary on $\mathrm{it}^{10}{ }^{10}$ and also the arithmetical sections of the Mathematics Useful for Understanding Plato by Theon of Smyrna ( $2^{\text {nd }}$ century AD). In some parts of the works of Theon and Iamblichus just mentioned we find, in addition to the account of the metaphysical and mathematical properties of number, a description of alleged mystic or symbolic properties of the first ten numbers. ${ }^{11}$ Nicomachus himself indulged in these arithmological ponderings, not in his Introduction but in a lost writing called

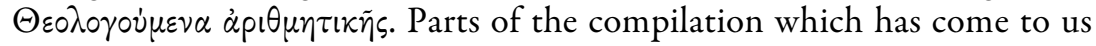
under that title, was edited by Ast and used to be ascribed to Iamblichus, may derive from Nicomachus' lost work. ${ }^{12}$ A third and different approach is represented by the 'Api $\theta \mu \eta \tau \leftarrow \alpha \dot{\alpha}$ by Diophantus of Alexandria, an algebraic work of crucial importance for the history of the discipline. This is a collection of one hundred and thirty problems giving numerical solutions for determinate equations (those with a unique solution), and indeterminate equations. ${ }^{13}$

Let us focus in particular on the first two approaches, starting from Euclid's arithmetical books. These are constituted by a set of twenty-two Definitions of terms, followed by three sets of Propositions, i.e. truths about the things denoted by the terms just defined: theorems. The Definitions and the Propositions concern the properties of and relationships between two items: (i) unit; and (ii) numbers. Let us consider an example of Euclid's modus operandi: his definitions of unit, number and numbers prime to one another on one side, and Proposition I on the other:

Df. 1. A unit is that by virtue of which each of the things that exist is called one. Df. 2. A number is a multitude composed of units... Df. 12. Numbers prime to one another are those which are measured by some number as common measure...

Proposition I. Two unequal numbers being set out, and the smaller being continually subtracted in turn from the greater, if the number which is left never measures the one before it until a unit is left, the original numbers will be prime to one another. ${ }^{14}$

10. $C f$. the remarks by Robbins 1926,126 .

11. Cf. e.g. Iamblichus, in Nic. 11.1-26; Theon, Expositio, 94.1-106.11. I owe both the point and the references to Vitrac 1990-2001 (vol. 2, 474).

12. Cf. Heath 1921, vol. 1, 97. For a sketch of Nicomachus' arithmological approach and its antecedents see the remarks of Robbins 1926, p. 89-92; the same approach is to be found in Anatolius of Alexandria.

13. Cf. O’Connor \& Robertson 1999.

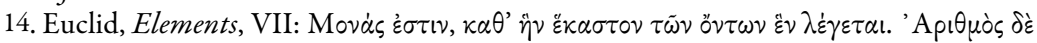

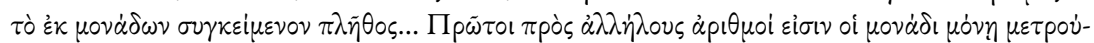

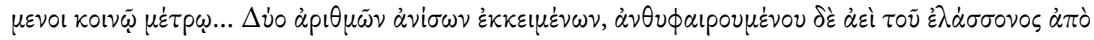


Two things are worth noting. First: the content of the arithmetical books, as the content of the other books of the Elements, is characterised by a deductive structure: the Propositions are derived from the Definitions by way of deductions. Given the definitions of unit, number, and numbers prime to one another - given what a unit, a number and the relationship being prime to one another amount to, it follows that Proposition I is true. ${ }^{15}$ Second: there is no metaphysics in Euclid's text. Euclid does not deal with the question of what it is for a number to exist: he just assumes that it exists. ${ }^{16}$

Let us now consider the second approach to arithmetic distinguished above; and let us deal, in particular, with Nicomachus' Introduction to Arithmetic. This treatise, as its title suggests, is an introduction to a dis-

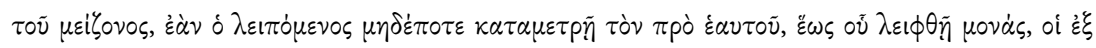

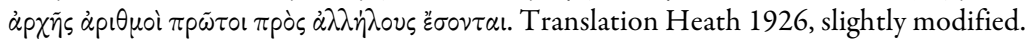

15. And indeed in Euclid's text Proposition I is followed by its proof: $\Delta \dot{\nu} \sigma \gamma \dot{\alpha} \rho[\dot{\alpha} v i \sigma \omega \nu]$

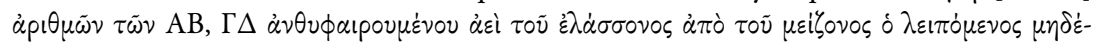

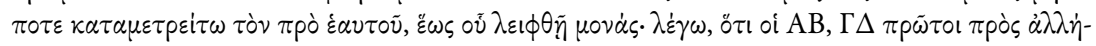

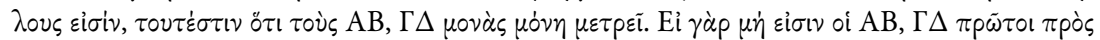

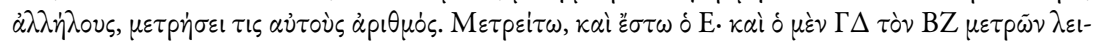

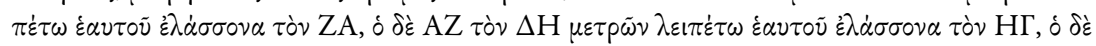

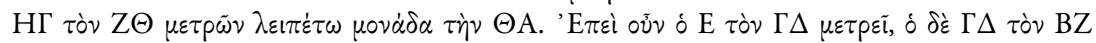

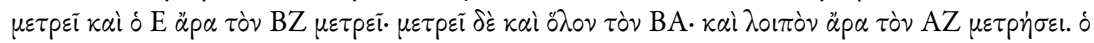

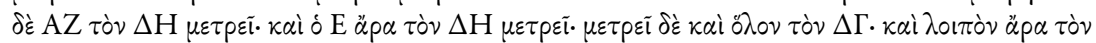

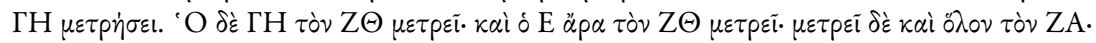

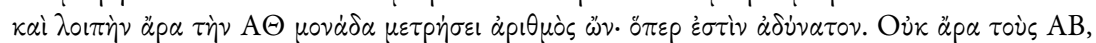

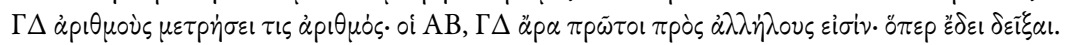

16. But doesn't Euclid at least appear to take one of the two main metaphysical lines on numbers drawn in Antiquity? The Platonists argued that numbers exist independently from countable items; the Aristotelians claimed that the existence of the former amounts to that of the latter. To put the point linguistically, number words have an adjectival ('One leg is good, two legs is better') and a substantival ('Two is twice one') use. It is the substantival use of number words - the one we adopt when we do arithmetic - which insinuates that numbers have a separate existence from countable items. One way to neutralise the point and argue for the Aristotelian position is to suggest that the substantival use is parasitical upon the adjectival use - i.e., roughly, that the meaning of the substantive 'two' is to be explained by reference to the meaning of 'two Fs' (see Barnes 1995, 87). Now Euclid defines 'unit' i.e. the things arithmeticians refer to when they say that 10 contains 3 more units than 7 in terms of 'one', the ordinary adjective we use in answering e.g. the question: 'How many legs did Long John Silver have?'; and insofar as he takes the substantive 'unit' to derive from the corresponding adjective, one might think that he is implicitly taking an Aristotelian line (rather than a Platonist line) on the metaphysical question of what it is, for a number, to exist. This is a tempting thought; but the temptation is appeased by the fact that Euclid's

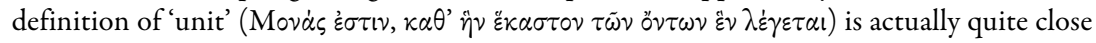

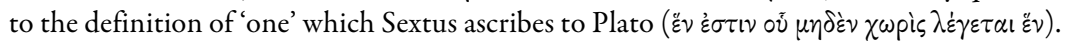


cipline: the arithmetical art. The discipline is characterized at the beginning of the treatise in contrast with other sciences, on the basis of a distinction between beings:

Beings, then, both those properly so called and those so called by homonymy (that is, both the objects of thought and the objects of perception), are some of them unified and continuous, for example, an animal, the universe, a tree, and the like, which are properly and peculiarly called 'magnitudes'; others are discontinuous, in a side-by-side arrangement, and, as it were, in heaps, which are called 'multitudes', a flock, for instance, a people, a heap, a chorus, and the like. Wisdom, then, must be considered to be the science of these two forms [i.e. magnitude and multitude].

Nicomachus then specifies that the science in question cannot be a science of magnitude and multitude per se, but of something separated from each of them: of quantity, set off from multitude; and of size, set off from magnitude. He concludes that

since of quantity one kind is viewed by itself, having no relation to anything else, as 'even', 'odd'... and the other is relative to something else and is conceived of together with its relationship to another thing, like 'double', 'greater', 'smaller'... it is clear that two sciences will lay hold of and deal with the whole investigation of quantity: the arithmetical art, absolute quantity; and music, relative quantity. ${ }^{17}$

He then distinguishes between two sciences which deal with size: geometry on one side, and astronomy on the other.

Let us focus on the crucial steps of Nicomachus' presentation. There are two kinds of beings (ov $v \tau)$ : the properly-called beings (i.e. the objects of thought: $v \circ \eta \tau \dot{\alpha}$ ), and the beings by homonymy (i.e. the objects of perception: $\alpha i \sigma \theta \eta \tau \dot{\alpha})$. In both cases we can distinguish further between beings

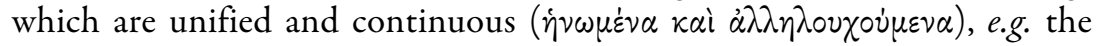
living, the world, the tree, which are called magnitudes $\left(\mu \varepsilon \gamma^{\prime} \theta \eta\right)$; and beings

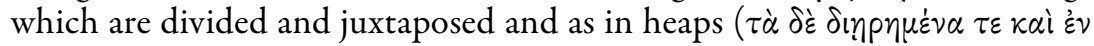

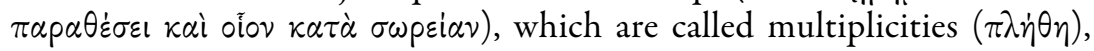

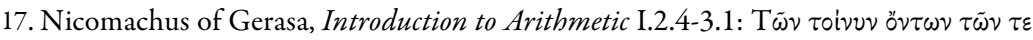

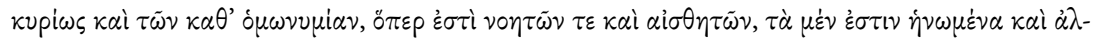

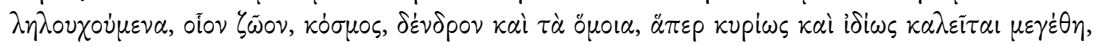

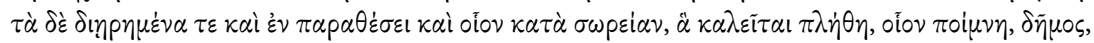

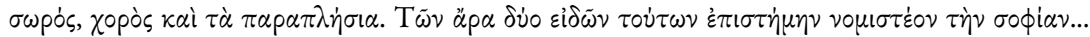

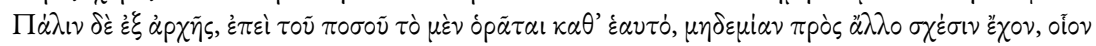

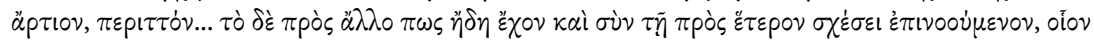

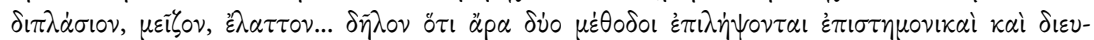

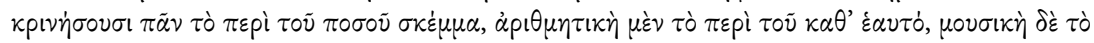

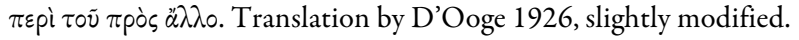


e.g. a flock, a people, a chorus. We have then the distinction of four sciences: two of them, the arithmetical art and the musical art, deal with two different aspects of the first kind of beings - multitudes; and the other two, geometry and astronomy, with two different aspects of the second kind of beings - magnitudes.

Nicomachus' presentation of the arithmetical art reminds us of Sextus' presentation of this discipline in M IV 1. Mutatis mutandis, both in Nico-

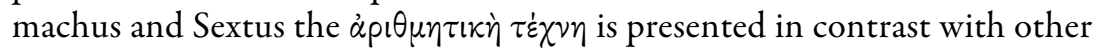
mathematical disciplines, on the basis of a distinction between continuous items - magnitudes - and discontinuous items - multiplicities. To say it with Sextus, the subject of geometry is a kind of continuous quantity: magnitude; and the subject of the arithmetical art is a kind of discontinuous quantity: number. The origin of this distinction is a passage of the Categories, 4b20-5a14, where Aristotle distinguishes between continuous and discontinuous quantities. Without pursuing this subject in depth here, we might follow the approach of White 1992 and sketch the Aristotelian characterization of continuous quantities as follows. If a quantity is continuous, then it can be divided in a certain way - in parts of a certain kind; if a quantity is discontinuous, then it can be divided in another way - in parts of another kind. More specifically, what is continuous cannot be divided into parts which are both jointly exhaustive (i.e. such that no part of the original whole is left out) and mutually disjoint (i.e. such that none of them overlaps any other); what is discrete or discontinuous can be divided into parts so characterized.

Nicomachus' Introduction is articulated in four parts, each dedicated to one of four fundamental themes concerning numbers. For every theme Nicomachus puts forward a classification of concepts constituted by a set of Definitions, followed by examples. The classifications are the following: (i) the classification of numbers considered in themselves, starting from the fundamental opposition even vs. odd, and of the species which those two genera split into; (ii) the classification of the numerical ratios, according to the ten categories of the relative quantity; (iii) the classification of the $f_{i-}$ gured numbers; (iv) the account of the theory of the ten proportions, which extends beyond arithmetic, but which is treated here, because it constitutes a subject preliminary to the ensemble of the mathematical studies. ${ }^{18}$

But here we are concerned more with the kind of discipline Nicomachus deals with rather than with the technical details of his study. Nicomachus' arithmetical art is devoted to a certain kind of being: number. It is, in this sense, a metaphysical discipline: it deals with number qua being. It 
copes with the question of what it is, for number, to exist (Nicomachus of course takes a Platonist line on the matter: number has an existence independent from numerables); and with the question if there is any kind of item whose existence depends on that of number, and any kind of item whose existence the existence of number depends on.

This as far as the subject matter of the arithmetical art is concerned; but what about its structure? In his introduction to the more recent French translation of Euclid's Elements, Caveing observes that

the Euclidean form is the demonstrative form which puts forward the reasons why the results of a science are necessarily true: it is distinct from other forms of expositions, which we have also specimens of - e.g. Nicomachus' Introduction to arithmetic, in which these reasons are not given, but the results are commented on from other points of view. ${ }^{19}$

In the same work Vitrac, after having made a comparison between Euclid's and Nicomachus' classification of even and odd number, emphasizes the very strict deductive structure which characterizes Euclid's sequence and is absent in Nicomachus' one, and explains this fact by suggesting that

the human intervention implied by a demonstration would risk making the reader believe in a conventional character of arithmetic's results. But these results, from Nicomachus' point of view, are an objective reality independent of our grasp of it, which it is right to describe, not to justify. ${ }^{20}$

Be that as it may, these judgments stress an unquestionable feature of Nicomachus' arithmetical art: it is a discipline, a sequence of propositions, characterized by a non-deductive structure. ${ }^{21}$

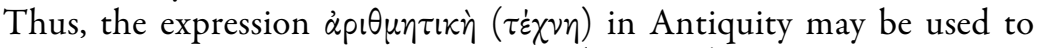
refer, in particular, to two quite different (kinds of) disciplines. The first one is the number theory we find in Euclid, Elements, VII, VIII and IX. It is a discipline devoted to unit and number. It has not got an explicitly metaphysical content (i.e. it does not explicitly discuss the question of/try to establish what it is for a number to exist). Like the discipline treated in Elements, I-VI, X-XIII, i.e. geometry, this discipline has a deductive structure. Its constituents divide into two classes: the first truths or principles (definitions, postulates or axioms), and the derived truths or theorems. Its

19. Op. cit. vol. 1, 114. The translation is mine.

20. Op. cit. vol. 1, 114. The translation is mine.

21. $C f$. also Heath 1921, vol. 1, 97-98: 'It is a very far cry from Euclid to Nicomachus. In the Introductio arithmetica... there are no longer any proofs in the proper sense of the word: when a general proposition has been enunciated, Nicomachus regards it as sufficient to show that it is true in particular instances; sometimes we are left to infer the general proposition by induction from particular cases which are alone given'. 
principles do not need proof: they are primary and self-explanatory. Its theorems are proved from its principles: the proofs, which must take the form of valid deductive arguments, explain the theorems and ground our knowledge of them on our knowledge of the principles. So Euclid's number theory has a finite and unitary set of principles, and it constitutes a closed body of explained or self-explanatory truths.

But $\dot{\alpha} \rho \theta \theta \eta \tau \iota k \grave{\eta}(\tau \dot{\varepsilon} \chi \nu \eta)$ in Antiquity may also be used to refer to a second kind of discipline: the discipline e.g. Nicomachus' Introduction to Arithmetic is devoted to, which we may call arithmetical art. This discipline also deals with the particular kind of discontinuous quantity Euclid's number theory deals with: number. But it differs from it at least in two respects. First: it considers a certain aspect of number - it deals with number qua being. In other words, Nicomachus' arithmetical art has a metaphysical subject. It is a discipline devoted to beings; and in particular, to those kinds of beings which are numbers - to the question of what it means, for a number, to exist; and (e.g.) to the question if there is any item whose existence depends on that of numbers. Second: Nicomachus' arithmetical art is not a deductive science; it has rather an expository character. It contains no demonstration; it is a set/a sequence of propositions which does not satisfy any of the defining-conditions of a demonstrative science.

\section{Sextus' targets in $M$ I-VI}

Now given those two different disciplines, which of them is attacked in Against the Arithmeticians? The answer is clear: Sextus, in $M$ IV, does not attack people like Euclid (and a discipline like the subject of his arithmetical books); ${ }^{22}$ he rather attacks people like Nicomachus (and a discipline like the subject of his Introduction to Arithmetic). ${ }^{23}$ And this is an interesting fact, particularly if we consider it in the light of what Sextus does in the preceding essay, Against the Geometers.

In this treatise, coherently with the general strategy he adopts in $M$ IVI, Sextus wants to show that geometry is not really an art, since it has no

22. Least of all does Sextus attack people like Diophantus and works like his algebraic treatise.

23. And also people like Theon, and Platonist or Neo-Pythagorean versions of the ג̇pl$\theta \mu \eta \tau i \kappa \eta$ which accounted for mystic and symbolic features of numbers in addition to their mathematical and metaphysical properties. As Brisson observes, 'Sextus' systematic demolition calls into question anything which could be taught by the Neo-Pythagoreans in the first centuries of our era', and that is 'a theoretical context in which naturally converge Pythagoreanism and Platonism, just as it was the case in the Ancient Academy of Speusippus and Xenocrates and in the middle Platonism' (Brisson 2006, 70). The translation and the italics are mine. 
object. He starts by attacking the procedure of the geometers (and others) of 'postulating their geometrical first principles by hypothesis ${ }^{24}$ (7-17). Sextus indicates that his targets are the $\dot{i} \pi 0 \theta \dot{\varepsilon} \sigma \varepsilon ı$ s understood in a specific sense, according to which 'we call hypotheses the first principles of proofs: for an hypothesis is the postulating of a fact for the establishing of something' (III 4); he then attacks the reasonableness of accepting any such first principle (7-17). ${ }^{25} \mathrm{He}$ subsequently tries to show the falsity, inconsistency and unacceptability of some of the principles of geometry in particular (18). Sextus attacks first the definitions of fundamental notions such as point, line, surface and body (19-93), and then derived notions such as straight line, angle and circle (94-107). Sextus' purpose is to show that the objects of the alleged geometrical truths are inconceivable. Some of his arguments concern the relation between geometrical objects of dimension $n$ (lines, surfaces, solids) and objects of dimension $n-1$ (points, lines, surfaces); others directly attack definitions, for instance on the grounds that there is some incoherence in them. ${ }^{26}$ In a final section (108116), Sextus trains his fire on the theorems or derived truths of geometry in particular, on the possibility of bisecting a given straight line.

The exact origin of Sextus' arguments and the identity of his adversaries have been debated. ${ }^{27}$ It appears that he targets a pretty elementary geometry

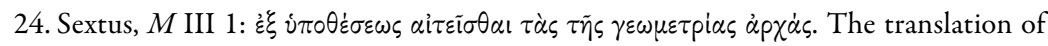
the passages from $M$ III is by Barnes 1990a, 95 .

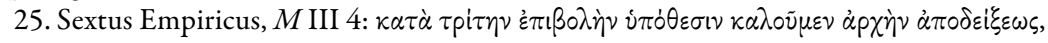

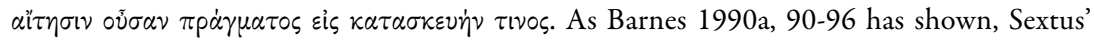
targets here are the hypotheses in a broad Aristotelian sense - the first or primary or primitive principles from which the remaining truths or theorems of a science are derived. Sextus has in mind a method of proof which begins by someone laying down certain propositions as first principles, an act which commits him to their truth and constitutes the starting point in the demonstration of a theorem. Sextus rightly supposes that this method is not peculiar to geometers, but common to anyone supposing that all knowledge depends on some principles; thus, before raising specific difficulties against some geometrical principles, he attacks the reasonableness of accepting any principle by means of the hypothetical mode (for a sharp analysis of Sextus' attack, see Barnes 1990a, 96-112).

26. Cf. Mueller 1982, 71-72.

27. What are Sextus' sources and who does he aims his refutations at? Sextus mentions no geometer but Eratosthenes ( $M$ III 28) and no title of geometrical treatise. As Dye and Vitrac 2009, 168 point out, Heiberg, the modern editor of Euclid, uses Sextus as a witness of the Euclidean tradition for Definitions I.2, 4, 8, 15 and Proposition I.10, which he would mention in $M$ III 29, 94, 100, 107 and 109. Heiberg believes that Sextus read the Elements (and that he had a correct text in comparison to that of Iamblichus: $c f$. Heiberg 1969-1977 vol. 4, LXXII); he is followed by Heath $(1926,62-63)$. This position is nuanced by Mueller 1982. He takes Sextus' target to be 'Euclidean geometry': if it is clear that Sextus puts forward and attacks (among other things) variants of Euclid's definitions of line, surface, 
which was taught in some philosophical (presumably Platonist) schools, rather than the advanced science of Euclidean geometry. Still, this geometrical discipline appears to be on the same wave length as Euclidean geometry in at least two respects: first, it is characterized by a deductive structure; and second, it does not have an explicitly metaphysical content. Now in $M I V$, as we have just seen, Sextus does not attack a discipline on the same wave-length as Euclidean geometry, such as the subject of Euclid's Elements VII, VIII and IX would have been. In other words, Sextus' targets in $M$ III and in $M$ IV are not homogenous.

The scenario we find in M IV, Against the Arithmeticians, is similar to the scenario we find in $M \mathrm{~V}$, Against the Astrologers. At the beginning of this treatise (V 1-3) Sextus clarifies the object of his inquiry: the astrology or the mathematical art. This is not the complete art composed by the arithmetical art and geometry - indeed, Sextus has already confuted the

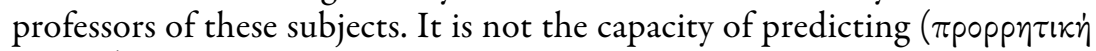

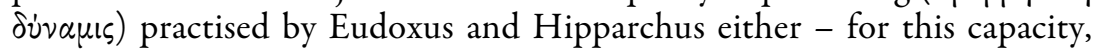
like agriculture and navigation, consists in the observation of the things which appear, from which it is possible to forecast draughts, and rainstorms and plagues and earthquakes and other changes in the surrounding vault of a similar character. Sextus' target is rather constituted by the horoscopes of the Chaldeans, which are opposed to ordinary life, build a great bulwark of superstition and do not allow us to do anything according to the right reason. ${ }^{28}$

body, straight line and circle, the provenance of Sextus' targets and arguments is not immediately obvious: and Mueller stresses the relationship between some of them and Stoic and Epicurean philosophizing. Cambiano 1999 adds further details: he suggests that Sextus' targets were likely to include, in addition to geometers such as Euclid and Heron, some philosophers, presumably Stoics, who took the definitions of some fundamental notions such as point, line and solid as relevant to philosophy. As for his arguments, Cambiano finds it likely that Sextus drew both from the Epicureans and the Academics. Most recently, Dye and Vitrac 2009 argue that Sextus' attack on the foundations of geometry does not aim at refuting the sophisticated presentations of this discipline offered by Euclid, Archimedes, Apollonius, Pappus or Eutocius, but rather the use of geometry made by mathematicians and philosophers to modelize the physical world along the lines of Plato's Timaeus. According to Dye and Vitrac, such technical geometrical treatises by Euclid and his colleagues as the Elements were used in the framework of a specialized education, while other more elementary writings, geometrical introductions, were used in a cycle of mathematical studies propaedeutic to philosophy imparted in some philosophical schools. The existence of these geometrical elementary handbooks is suggested by Nicomachus himself (who in his Introduction to Arithmetic II.6.1 mentions an Introduction to geometry: $c f$. Heath 1921, vol. 1, 97), but none of them has survived.

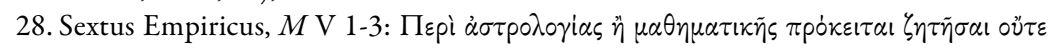

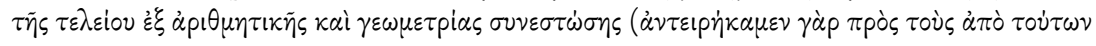


Sextus' target, here, has nothing to do with a deductive science mathematical astronomy; it is constituted by the pseudo-science of astrology. What about the second discipline which Sextus distinguishes astrology from, and does not attack? Sextus mentions, among its heroes, Eudoxus..$^{29}$ In astronomy Eudoxus was the first Greek to construct a mathematical system, that of the homocentric spheres, to explain the apparent motions of the heavenly bodies. The system is described by Simplicius (in Cael. $492.31 \mathrm{ff}$.). But Eudoxus was also famous for his more practical and very influential description of the constellations, with calendaric notices of

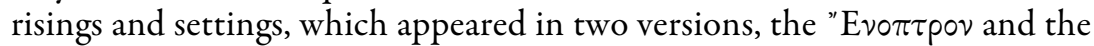

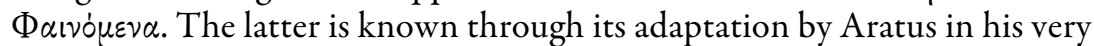
popular poem of the same name. The commentary of Hipparchus on both Eudoxus and Aratus is extant.

The second discipline mentioned by Sextus should not be identified with Eudoxus' mathematical astronomy, ${ }^{30}$ but rather with his work on constellations. Sextus does not attack it on the ground that it amounts to an observation of the things which appear (like farming and navigation) by means of which weather can be predicted. But is Sextus justified in describing Eudoxus' astronomy in these terms? Barnes expresses some doubts:

the description is scarcely true to the historical achievements of Eudoxus, whose aim is nothing if not theoretical; but Sextus is determined to construe his work as nothing more than the observation of phenomena... ${ }^{31}$

This latter point needs to be emphasized. In a couple of treatises of $M$ IVI Sextus puts forward a contrast between a practical art on one side, which he accepts and does not attack, and a theoretical counterpart of it on the other, which he aims to refute. At the beginning of Against the Grammarians Sextus remarks that the term $\gamma p \alpha \mu \mu \alpha \tau i \kappa \eta$ is ambiguous: it may

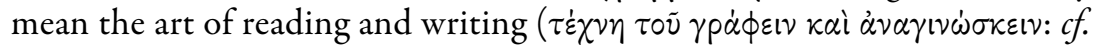
$M$ I 49), normally called $\gamma p \alpha \mu \mu \alpha \tau \iota \sigma \tau \iota k \dot{n}$, and it may mean the technical dis-

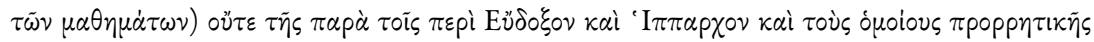

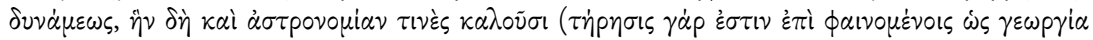

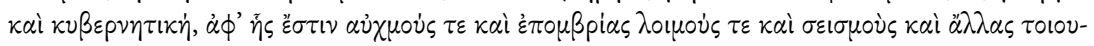

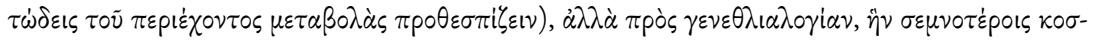

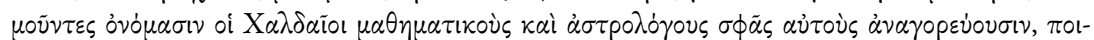

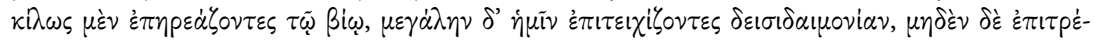

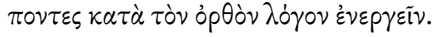

29. I owe the account of Eudoxus which follows to Toomer \& Jones $2012^{4}, 546$.

30. Which Sextus does not discuss 'perhaps because of its reliance on the methods of arithmetic and geometry, but perhaps because he has no particular objections to raise against it' (Mueller 2004, 63).

31. Barnes 1988, 71 . 
cipline developed by the scientific grammarians, which amounts to the knowledge of letters in their more varied and expert theorems ( $\dot{\varepsilon} \pi \dot{\imath} \tau \dot{\eta} \nu \dot{\varepsilon} \nu$

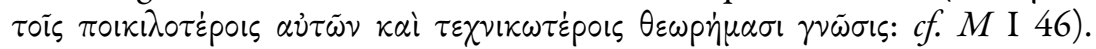
Sextus then explains that it is not his plan to speak against the former, but against the latter (I 49).

A distinction similar to that of grammatistic $v$ s. grammar is to be found at the beginning of Against the Musicians. The term 'music' is used in different senses:

in one as a science dealing with melodies and notes and rhythm-making and similar things... in another sense it connotes instrumental skills, as when we describe those who use flutes and harps as musicians and female harp players as musicians... While music, then, is conceived in all these ways, it is certainly not our present purpose to frame our refutation of it if conceived in any other sense than the first signified. ${ }^{32}$

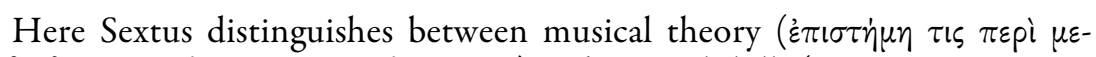

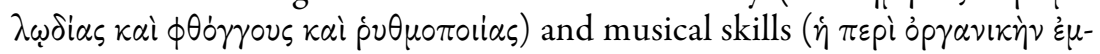
$\pi \varepsilon i p(\alpha)$, and resolves to attack only the former.

In order to understand the contrast between practical and theoretical arts at stake in those passages, let us go back to Against the Grammarians. The grammarians offered, by their art, a criterion for discriminating good Greek from bad. In their opinion, in order to speak good Greek the speaker must possess the grammatical art: he must know a set of theorems which enables him to determine, between two alternative expressions, which of them is correct. Here is an example put forward by Sextus in M I 197. We have to establish which of two expressions, $\chi \rho \tilde{\alpha} \sigma \theta \alpha \iota$ or $\chi \rho \tilde{\eta} \sigma \theta \alpha \mathrm{l}$, is well said. The Grammarians answer: $\chi \rho \tilde{\alpha} \sigma \theta \alpha$. Why? Because (i) $\chi p \tilde{\eta} \sigma \iota s$ and $\kappa \tau \tilde{\eta} \sigma \iota s$ are analogous; (ii) $\kappa \tau \tilde{\alpha} \sigma \theta \alpha \mathrm{l}$, and not $\kappa \tau \tilde{\eta} \sigma \theta \alpha \mathrm{l}$, is well said; therefore (iii) $\chi \rho \tilde{\alpha} \sigma \theta \alpha$, not $\chi p \tilde{\eta} \sigma \theta \alpha \mathrm{l}$, is well said. ${ }^{33}$ The underlying idea is that if two substantives $(\chi p \tilde{\eta} \sigma \varsigma$ and $\kappa \tau \tilde{\eta} \sigma \varsigma \zeta)$ are analogous - i.e. they have the same ending, then the derived verbs are analogous - and therefore they have the same ending.

Sextus rejects any such technical criterion:

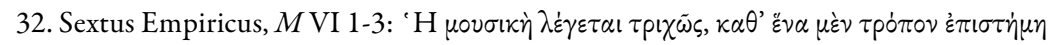

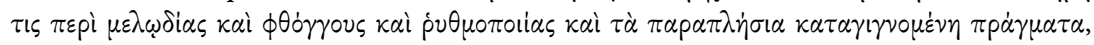

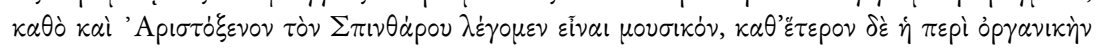

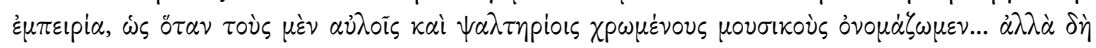

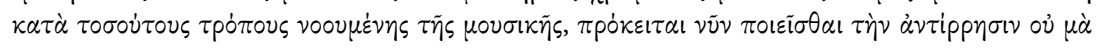

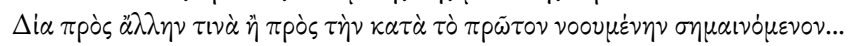

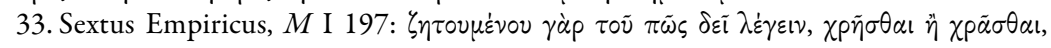

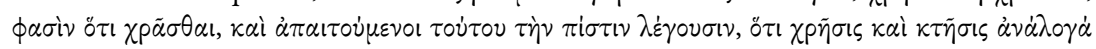

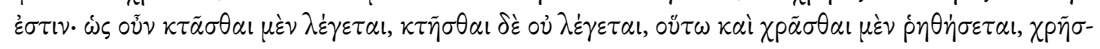

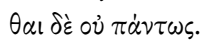


The criterion of what is well said and what is not will be not some technical theory of grammar but the non-technical and informal observation of usage. $^{34}$

Those who want to speak correctly should attend to the non-technical and informal observation... of the usage of most people and of what they accept as Greek or reject as not Greek. ${ }^{35}$

The key words here are $\pi \alpha p \alpha \tau \dot{p} \eta \sigma i \varsigma$, observation and $\sigma u v \dot{\theta} \theta \varepsilon 1 \alpha$, common usage. Instead of technical theory, Sextus suggests, let us stand by untutored observation. Let us observe ordinary usage, see what usages people accept and what they reject, and take this as a criterion of correctness. ${ }^{36}$

Now it is reasonable to imagine that what is said of the theoretical art of grammar and the practical art of grammatistic in $M \mathrm{I}$ is a special case of what could be said throughout $M$ I-VI about the theoretical sciences attacked by Sextus on one hand and their corresponding practical counterparts accepted by him on the other. In order to complete our sketch of such a contrast, one last detail must be added. In characterizing some of the practical arts he does not attack, Sextus makes reference to $\tau \dot{\alpha} \phi \alpha \iota v \dot{\mu} \mu \varepsilon v \alpha$, the things which appear. We have seen that Sextus describes the good astronomy of Eudoxus as 'observation of the things which appear'. That this description is true to the historical achievements of Eudoxus is questionable, as we have seen; still, it gives us a clue of what the science of astronomy should amount to in order to be acceptable for a sceptic. It should be nothing more than the observation of phenomena, similar to the observation of common usage. A good grammarian does not theorize about language: he reports common usage. A good astronomer does not theorize about the nature of things; he observes what seems to be the case. Elsewhere, Sextus puts forward a similar characterization of a sceptically acceptable counterpart of the theoretical medicine: the good doctor is a mere observer and recorder of phenomena. ${ }^{37}$ The emphasis on observation and phenomena recalls the conception of medicine characteristic of the medical school to which Sextus himself is said to have belonged, medical empiricism. The Empirical doctors relied on 'experience', or $\dot{\varepsilon} \mu \pi \varepsilon i p i \alpha$ : they accumulated observations concerning which types of phenomenon have

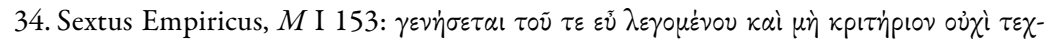

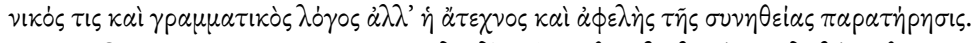

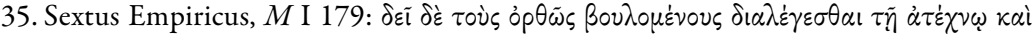

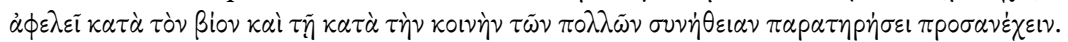

36. Cf. Barnes 1988, 69. For an analysis of Sextus' invitation to stick to common usage, cf. Corti 2009, 206-219; for a defense of this invitation in the spirit of a Wittgensteinian 'use' theory of meaning, $c f$. Corti 2009, 220-235.

37. $M$ V 103-104: $c f$. Barnes 1988, 71-72 on this passage. 
tended to go with which (e.g. wounds to the heart with death), and what sort of intervention has been seen to help in which type of case (e.g. eating pomegranates in cases of diarrhoea); then they recalled these memories to provide the appropriate remedy (pomegranates) for a given pathological symptom (diarrhoea). ${ }^{38}$ So the practical counterparts of theoretical sciences, such as grammatistic, musical skills and medicine, are based on the observation ( $\tau \dot{\eta} p \eta \sigma \iota \varsigma)$ of the common usage $(\sigma \nu v \dot{\eta} \theta \varepsilon ı \alpha)$ and of the things which appear ( $\tau \dot{\alpha} \phi \alpha \iota v \dot{\alpha} \mu \varepsilon v \alpha)$; and they do not pretend to discourse about nature $(\dot{v} \sigma(\varsigma)$. But they are genuine arts: they contain universal generalisations and they exhibit a systematic structure.

Sextus' acceptance of the practical arts as opposed to their theoretical counterparts suggests that it should be possible, for a sceptic, to acquire and exercise them without having any beliefs. Is this a reasonable thought? Barnes has defended such a view in a persuasive way. He distinguishes between a formal and informal learning. Formal learning involves a teacher and a learner: the teacher has knowledge, which he articulates in a system of propositions; he teaches his pupil by declaring these propositions; and the pupil learns insofar as he thereby comes to acquire the teacher's beliefs. Informal learning involves a master and an apprentice: the master possesses some skill, which he evinces in his practice; he teaches his apprentice by showing his skill; and the apprentice learns insofar as he thereby comes to acquire the skill which his master possesses. Formal learning involves the possession and transmission of beliefs. A Pyrrhonist - by definition - cannot make judgements nor acquire beliefs; therefore he cannot formally learn. But informal learning invokes no beliefs; and thus, it seems perfectly compatible with Pyrrhonism. Pyrrhonists have capacities and practical skills of various sorts: they can read and write; they can play music; some of them can heal the sick. These capacities can be acquired by a Pyrrhonist: for such informal learning does not depend upon any mental attitude which a Pyrrhonist must lack. ${ }^{39}$

38. Cf. Hankinson 1998, 308-309: 'The Empiricist... builds up a collection of observations where particular types of event are seen to follow one another...: if it becomes sufficiently large it will generate a general rule, or theorem. These theorematic relations between observable events need be neither universal nor positive: the Empiricists employ a fivefold typology of connection and disjunction, according to whether things are seen to go together always, for the most part, half the time, or never... These categories stand in rarely determinate logical relations: always $p$ if and only if never not- $p$; for the most part $p$ if and only if rarely not- $p$; half the time $p$ if and only if half the time not- $p$. And all of them are of value in isolating appropriate therapies and rejecting others... All that matter for the Empiricists are the appearances, the phainomena...'.

39. Cf. Barnes 1988, 61. 
This distinction between a practical skill which is acceptable for the sceptic and a corresponding theoretical science which the sceptic refuses and attacks, though, is not to be found uniformly in Against the Professors. The scenario in this work, as far as the disciplines attacked and accepted by Sextus are concerned, is roughly the following. In $M$ I and $M$ VI we have a contrast between a theoretical art or science which is attacked (grammar and musical science), and a corresponding practical art which is accepted (grammatistic and musical skills). In $M \mathrm{~V}$ we find a distinction between a pseudo-science (astrology), which is attacked, and what is construed as a predictive capacity, but appears to have a theoretical aim, Eudoxus' astronomy, which is accepted. In $M$ IV Sextus' target is a non-deductive, metaphysical discipline: the 'Pythagorean' arithmetical art. We find no reference to a practical counterpart of the arithmetical art in this treatise; but in the parallel passage PH III 151 Sextus accepts the capacity of counting and calculating. In $M$ III Sextus' target is a scientific discipline displaying the demonstrative and non-metaphysical characteristics of Euclidean geometry; and in $M$ II rhetoric, presented as the science of speech $(\dot{\varepsilon} \pi \imath \sigma \tau \dot{\eta} \mu \eta$ $\lambda \dot{\gamma}(\omega v)$.

\section{Scepticism, sciences and appearing}

The scenario is quite puzzling. Even if Sextus presents $M$ I-VI as a unified treatise, he seems to have different ideas (and different kinds of target) in mind in each of them. In some treatises of $M$ I-VI (or better: in some parts of $M$ I-VI), demonstrative sciences are attacked, and the corresponding practical skills are accepted. In others, pseudo-sciences are attacked, and sciences which Sextus construes as practical skills are accepted. In others, a demonstrative science or a non-demonstrative discipline is attacked, and no counterpart of it is accepted. This textual fact raises several questions; in the following lines I will focus in particular on one of them. What does Sextus have in mind in $M$ III, where he attacks a discipline on the same wave length as the demonstrative science par excellence, Euclidean geometry, and in $M \mathrm{~V}$, where he construes Eudoxus' astronomy as a practical skill and accepts it? What does make it possible, for Sextus, to construe Eudoxus' astronomy as an empirical art? And why doesn't Sextus accept, in some cases, non-theoretical counterparts of the disciplines he attacks?

One answer can be the following. Some theories or sciences are such that you can master them without having any beliefs; other theories or sciences are such that you cannot master them without having any beliefs. Some theories are such that grasping their primary truths (can) amount to being capable of doing something; other theories are such that grasping 
their primary truths cannot amount to being capable of doing something. My knowledge that 'Ann' designates Ann amounts to nothing but knowing how to use the name 'Ann'. I grasp that 'Ann' designates Ann insofar as I use 'Ann' to designate Ann and I realize that, when you utter 'Ann is here', you refer to Ann - I don't need to have any beliefs about what the name designates..$^{40}$ But can I grasp the postulate 'Parallel lines however far extended never cross' in a similar sort of way? Mustn't I have at least some beliefs (say about what parallel lines are) in order to master that truth? If this is the case, the fact that one can or cannot master a science without beliefs must depend on the nature of its primary truths.

An important distinction might be pertinent here. Sextus often employs, sometimes confusingly, a twofold division between types of items of

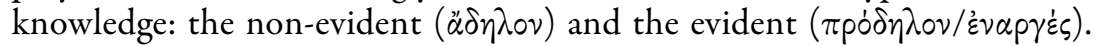
He presents this distinction in PH II 97-98 and in MVIII 145-147. Let us have a look at the first of these texts, focusing in particular on the distinction between evident objects and by nature non-evident objects:

Some objects, then, according to the Dogmatists, are evident, and some are non-evident. And of the non-evident, some are non-evident once and for all, some are non-evident for the moment, and some are non-evident by nature. What comes of itself to our knowledge, they say, is evident (e.g. that it is day)... and what does not have a nature such as to fall under our evident grasp is non-evident by nature (e.g. imperceptible pores - for these are never apparent of themselves but would be deemed to be apprehended, if at all, by way of something else, e.g. by sweating or something similar)... ${ }^{41}$

The origin and nature of this characterization have been widely discussed. ${ }^{42}$ For my present purpose, though, it will be enough to sketch the

40. For this way of granting the Pyrrhonist a linguistic mastery see Corti 2009, 221-235 and 249-259.

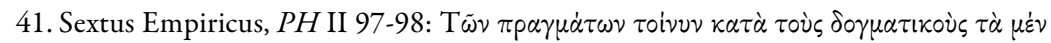

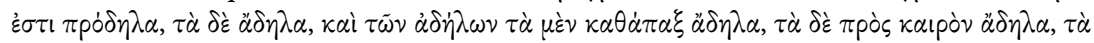

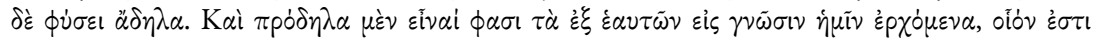

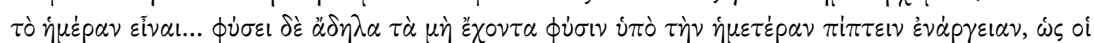

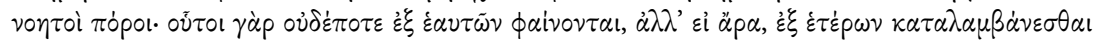

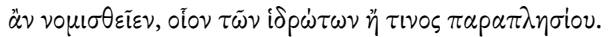

42. The contrast between evident ( $\pi$ pó $\delta \eta \lambda \alpha / \dot{\varepsilon} v \alpha p \gamma \dot{\eta})$ and non-evident $(\alpha \delta \eta \lambda \alpha)$ objects is an old one. Hankinson traces it back to the Hippocratic treatise On the Art, in which the author distinguishes between 'open' ( $\phi \alpha \nu \varepsilon p \dot{\alpha})$ diseases, occurring on the surface of the body, and hidden $(\alpha \delta \eta \lambda \alpha)$ diseases, 'peculiar to the bones and to the hollows of the body': see Hankinson 1987a, 88 and 1987b, 331 n. 12. The distinction between different kinds of non-evident objects grounds that between two kinds of signs, the indicative and the commemorative (PH II 99-102; $M$ VIII 148-58). Hankinson takes the former distinction to be Stoic (Hankinson 1987b, 338 n. 32). The latter has often been taken to be Stoic; Ebert 
basic idea of the distinction between the by nature non-evident objects, and the evident objects. We might express this distinction in propositional terms as follows:

- It is evident to $x$ at $t$ that $P$ iff $x$ can know that $P$ directly at $t$, without using an inference, whether on the basis of perception or through some sort of intellectual intuition.

- It is by nature non-evident to $x$ that $P$ iff $x$ can know that $P$ only by means of an inference - on the basis of other pieces of knowledge of his.

For instance, it is evident to me now that it is raining: I can come to know that it is raining just by looking out of the window. By contrast, it is by nature non-evident to me that there are invisible pores in my skin. I can come to know that only by making an inference from another piece of knowledge of mine: for instance, my justified belief that I sweat.

This distinction implies, I think, that the by nature non-evident objects such as the invisible pores or the soul or Providence cannot appear - they cannot produce any appearing. If an object appears to you to have a certain feature now, then you can grasp that feature of that object not by means of an inference. So if you can grasp the features of an object only by way of an inference, then it cannot do any appearing. Therefore a by nature nonevident object cannot do any appearing. Can imperceptible pores appear round to me at the moment? Can your soul appear to me to be in your body at the moment? Can Providence appear to me to exist at the moment? The answer to these questions is, I think: No. Evident objects can produce appearing; by nature non-evident objects cannot do so. Now it seems to me that abstract numbers and abstract geometrical items (maybe insofar as they are abstract) are by nature non-evident items - they cannot do any appearing. Can the number 47 appear prime to you at the moment? It seems to me that nothing could count as a number's appearing in that sort of way.

The claim that only evident items can appear calls for two clarifications. First: it is worth distinguishing that thesis from the thesis that only perceptible items can appear. Sextus - like everyone else in antiquity - presupposes that things may be evident to the mind as well as to the senses: so he surely won't be leaning on that second thesis. Second: a distinction bet-

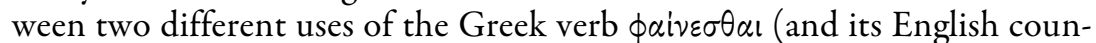
terparts 'to appear' or 'to seem') is crucial here. These verbs may be used in a judgmental way, to express the fact that one is inclined to judge or believe something ('It seems to me that I have closed the door, but I'll check that 
again'). But they may also be used in a phenomenological way, to denote the fact that things look, appear in a certain way - which does not imply being inclined to judge or believe something ('I have just tried your honey and it appears to me to be bitter, but I am not inclined to believe that it is: it may taste thus to me only because I am sick'). The impressions or appearances at stake in the sceptic texts and in the claim that only evident items can appear are psychological events of the latter kind. The claim amounts to saying that if $x$ is a by nature non-evident object, then $x$ cannot seem or appear to you to be $F$ in the second sense of 'appear' distinguished above; still, it is perfectly possible for you to have the judgmental impression that $x$ is $F$ - that is, to be inclined to judge or believe so. ${ }^{43}$ As far as the claim goes, you can be inclined to believe that the number $37,491,317$ is prime; but you cannot have the phenomenological impression that this is so.

Thus, not every object can appear $F$ to someone: some objects can do some appearing, other objects cannot do any appearing. On the basis of this distinction between objects we can draw a distinction between propositions. Some propositions contain terms which denote things which can do some appearing, such as honey and wine and sticks; other propositions contain terms which denote objects which cannot do any appearing, such as numbers and imperceptible pores and points. And on the basis of these distinctions between objects and propositions we can draw a distinction between sciences or theories. Some sciences are about objects which can do some appearing - they are constituted by propositions which contain terms denoting such objects; other sciences are about objects which cannot do any appearing - they are constituted by propositions which contain terms denoting such objects.

Now let us recall Sextus' characterization of the practical counterparts to theoretical sciences accessible to the sceptic: these skills amount to the 'observation of things which appear' - i.e. the observation of items which produce appearing. If a theoretical science deals with objects which produce some appearing, then there may be a practical counterpart to it accessible to the sceptic. Eudoxus' astronomy deals with planets, which appear to have certain features. So we can (in principle) construe Eudoxus' astronomy as a science acceptable for the sceptic. But there are other theoretical sciences, such as geometry, which deal with objects that cannot do any appearing, like abstract points and lines: and there cannot be a practical counterpart to them. For, if the empirical counterpart of a theoretical science amounts to the observation of the things which appear, and some objects cannot appear, then there cannot be an empirical science of such

43. For a characterization of the sceptic appearances see Frede 1973, 809-810; Barnes 1980, 491 n. 1; Burnyeat 1979, 34-35 and 43-46; Barnes 1990b, 2623. 
objects. So Sextus, as a sceptic, cannot accept those sciences; nor, of course, other non-deductive disciplines such as the arithmetical art which also deals with objects which cannot do any appearing: number qua being.

If this is the case, we may manage to explain the apparent oddness of Sextus throughout $M$ I-VI. When, given the nature of the science at stake, a practical counterpart is available, Sextus accepts it. When, given the nature of the science at stake, it can be construed as the observation and recording of phenomena, Sextus accepts it; and when, given the nature of the discipline at stake, it is such that there cannot be any empirical or practical counterpart to it, then Sextus does not mention - and of course he does not accept - any such thing. Sextus' different attitudes result from the different nature of his targets, and leave his modus operandi coherent. ${ }^{44}$

44. This paper is an outcome of my research project 'Scepticism, Metaphysics and Sciences'. A first stage of the project has been funded by the Swiss National Science Foundation and developed at the Faculty of Classics at the University of Cambridge (PA001-$115325 / 1)$; a second stage has been funded by the EU and developed at the UMR 8546, ENS Paris (FP7-Marie Curie IEF-275852). The paper has particularly benefitted from remarks from Jonathan Barnes, Myrto Hatzimichali, Marwan Rashed, David Sedley, and an anonymous reviewer for Philosophie Antique. I am very grateful to them all, as well as to the organizers and audiences of the conferences in Buenos Aires and Paris where this work has been presented and discussed. 


\section{BIBLIOGRAPHY}

ANNAS, J. \& J. BARnes 1994 (ed. \& tr.): Sextus Empiricus. Outlines of Scepticism, Cambridge, 1994 ( $2^{\text {nd }}$ ed. 2000).

BARNES, J. 1980: "Aristotle and the Methods of Ethics", Revue Internationale de Philosophie, vol. 34, 133-134 (1980), p. 490-511.

- 1988: "Scepticism and the Arts", in R. J. Hankinson (ed.), Method, Medicine and Metaphysics: Studies in the Philosophy of Ancient Science, Edmonton, 1988 (= Apeiron, $21.2[1988])$, p. 53-77.

- 1990a: The Toils of Scepticism, Cambridge, 1990.

- 1990b: "Pyrrhonism, Belief and Causation. Observations on the Scepticism of Sextus Empiricus", Aufstieg und Niedergang der Römischen Welt, II, 36.4, Berlin, 1990, p. 2608-2695.

- 1995: The Cambridge Companion to Aristotle, Cambridge, 1995 (The Cambridge Companions to philosophy).

Barnes, J. \& J. Brunschwig, M. Burnyeat, M. Schofield 1982 (ed.): Science and Speculation: Studies in Hellenistic Theory and Practice, Cambridge, 1982.

BRISSON, L. 2006: "Contre les arithméticiens... ou contre ceux qui enseignent que les nombres sont des principes", in J. Delattre (ed.), Sur le Contre les professeurs de Sextus Empiricus, Villeneuve d'Ascq, 2006, p. 67-77 (Travaux et recherches, Université de Lille 3).

BUrkerT, W. 1972: Lore and Science in Ancient Pythagoreanism, tr. [with rev.] by E. L. Minar, Cambridge (Mass.), 1972.

BURnYeAT, M. 1979: "Can the sceptic live his scepticism?", in M. Schofield, M. Burnyeat \& J. Barnes (ed.), Doubt and Dogmatism, Oxford, 1979, p. 20-53.

- 1982: "The Origins of Non-Deductive Inference", in J. Barnes \& al. (ed.), 1982, p. 193 238.

Bury, R. G. 1933 (tr.): Sextus Empiricus. IV, Against the Professors, London, 1948 (The Loeb Classical Library. Greek authors, 382).

Cambiano, G. 1999: "Philosophy, science and medicine", in K. Algra, J. Barnes, J. Mansfeld, M.Schofield (ed.), The Cambridge History of Hellenistic Philosophy, Cambridge, 1999, p. 585-614.

CorTI, L. 2009: Scepticisme et langage, Paris, 2009 (Bibliothèque d'histoire de la philosophie).

— forthcoming: "Sextus, the number two and the Phaedo", in P. D'Hoine, M.-A. Gavray, S. Delcominette (ed.), Ancient Readings of Plato's Phaedo, Leiden, forthcoming.

D’Ooge, M. L. 1926 (tr.): Nichomachus of Gerasa. Introduction to Arithmetic, with studies in Greek arithmetic by F. E. Robbins \& L. C. Karpinski, New York, 1926 (University of Michigan Studies. Humanistic series, 16).

Dye, G. \& B. Vitrac 2009: "Le Contre les géomètres de Sextus Empiricus: sources, cibles, structure”, Phronesis, 54/2 (2009), p. 155-203.

EBERT, T. 1987: "The Origin of the Stoic Theory of Signs in Sextus Empiricus", Oxford Studies in Ancient Philosophy, 5 (1987), p. 83-126.

Frede, M. 1973: Review of C. L. Stough's Greek Scepticism: A Study in Epistemology (Berkeley, 1969), The Journal of Philosophy 70 (1973), p. 805-810.

Glidden, D. 1983: “Skeptic Semiotics”, Phronesis, 28/3 (1983), p. 213-255.

HANKINSON, R. J. 1987a: "Evidence, Externality and Antecedent: Inquiries into Later Greek Causal Concepts”, Phronesis, 32/1 (1987), p. 80-100. 
- 1987b: "Causes and Empiricism: A Problem in the Interpretation of Later Greek Medical Method", Phronesis 32/3 (1987), p. 329-348.

- (ed.), Method, Medicine and Metaphysics: Studies in the Philosophy of Ancient Science, Edmonton, 1988 (= Apeiron, $21.2[1988]$ )

- 1998 : The Sceptics, London-New York, 1998 [1995].

Heath, Th. L. 1921: A History of Greek Mathematics: 1. From Thales to Euclid. 2. From Aristarchus to Diophantus, Oxford, 1921.

- 1926 (tr.): Euclid. The Thirteen Books of the Elements, vol. 1-3, second ed. rev. with additions, Cambridge, 1926.

HeIBERG, J. L. 1969-1977 (ed.): Euclid. Elementa, vol. 1-5, Leipzig, 1969-1977 (Bibliotheca scriptorum graecorum et romanorum Teubneriana).

Hoche, R. 1866 (ed.): Nichomachus of Gerasa. Nichomachi Geraseni Pythagorei Introductionis arithmeticae libri I et II, Leipzig, 1866 (Bibliotheca scriptorum graecorum et romanorum Teubneriana).

MAU, J. 1961 (ed.): Sexti Empirici opera. 3. Adversus Mathematicos I-VI, rec. H. Mutschmann, iterum ed. J. Mau, Leipzig, 1961 (Bibliotheca scriptorum graecorum et romanorum Teubneriana).

MUeLleR, I. 1982: “Geometry and Scepticism”, in Barnes \& al. (ed.) 1982, p. 69-95.

- 2004: "Remarks on Physics and Mathematical Astronomy and Optics in Epicurus, Sextus Empiricus, and Some Stoics", in Ph. Lang (ed.), Re-inventions: Essays on Hellenistic \& Early Roman Science, Edmonton, 2004 (=Apeiron, 37.4 [2004]), p. 57-87.

Mutschmann, H. 1914 (ed.): Sexti Empirici opera. 2. Adversus Mathematicos VII-XI, Leipzig, 1914 (Bibliotheca scriptorum graecorum et romanorum Teubneriana).

- 1958 (ed.): Sexti Empirici opera. 1. Pyrrōneion hypotypōseōn libros tres continens, Editionem stereotypam emendatam curavit addenda et corrigenda adiecit J. Mau, Leipzig, 1958 (Bibliotheca scriptorum graecorum et romanorum Teubneriana).

O'CONNOR, J. J. \& E. ROBERTSON 1999: Diophantus of Alexandria, in Mac Tutor History of Mathematics Archive, St. Andrews, 1999 (http://www.history.mcs.st-andrews. ac.uk/Biographies/Diophantus.html).

Pellegrin, P. 2002 (dir.): Sextus Empiricus. Contre les professeurs, trad. par C. Dalimier, D. Delattre, J. Delattre [et al.], Paris, 2002 (Points. Essais, 489).

RobBins, F. E. \& L. C. KARPINSKI 1926 : “Studies in Greek Mathematics” in D’Ooge (tr.) 1926, p. 3-177.

Sedley, D. N. 1982: “On Signs”, in Barnes \& al. (ed.) 1982, p. 239-272.

Spinelli, E. 2010: "Pyrrhonism and the Specialized Sciences", in R. Bett (ed.), The Cambridge Companion to Ancient Scepticism, Cambridge, 2010 (Cambridge Companions to Philosophy), p. 249-264.

TOOMER, G. J./A. JONES 2012: 'Eudoxus of Cnidus', in S. Hornblower, A. Spawforth (eds.), The Oxford Classical Dictionary, Oxford, 2012'.

VitraC, B. 1990-2001 (tr.): Euclide. Les Éléments, vol. 1-4, Paris, 1990-2001 (Bibliothèque d'histoire des sciences).

White, M. J. 1992: The Continuous and the Discrete: Ancient Physical Theories from a Contemporary Perspective, Oxford, 1992. 